\title{
SLOT EXCHANGE AND PURCHASE PLANNING OF SHORT SEA SERVICES FOR LINER CARRIERS
}

\author{
Hua-An Lu \\ Department of Shipping and Transportation Management, National Taiwan Ocean University, \#2, Pei-Ning Rd., \\ Keelung 202, Taiwan, R.O.C, halu@mail.ntou.edu.tw \\ Shu-Ling Chen \\ Department of Maritime and Logistics Management, Australian Maritime College Locked Bag 1397Launceston, \\ Tasmania, 7250, Australia. \\ Peter Lai \\ Business Division-Asia Service Department, Yang Ming Marine Transport Corporation, \#271, Ming De 1st Rd., Cidu, \\ Keelung 206, Taiwan, R.O.C.
}

Follow this and additional works at: https://jmstt.ntou.edu.tw/journal

Part of the Business Commons

\section{Recommended Citation}

Lu, Hua-An; Chen, Shu-Ling; and Lai, Peter (2010) "SLOT EXCHANGE AND PURCHASE PLANNING OF SHORT SEA SERVICES FOR LINER CARRIERS," Journal of Marine Science and Technology. Vol. 18: Iss. 5, Article 11.

DOI: $10.51400 / 2709-6998.1919$

Available at: https://jmstt.ntou.edu.tw/journal/vol18/iss5/11

This Research Article is brought to you for free and open access by Journal of Marine Science and Technology. It has been accepted for inclusion in Journal of Marine Science and Technology by an authorized editor of Journal of Marine Science and Technology. 


\section{SLOT EXCHANGE AND PURCHASE PLANNING OF SHORT SEA SERVICES FOR LINER CARRIERS}

\section{Acknowledgements}

This research was partially supported by a grant (NSC96- 2416-H-019-008) from the National Science Council of Taiwan. We also thank Mr. Jackie Chen, manager of Yang Ming Marine Transport Corporation, for providing valuable knowledge and practical viewpoint regarding alliance co-operation. 


\title{
SLOT EXCHANGE AND PURCHASE PLANNING OF SHORT SEA SERVICES FOR LINER CARRIERS
}

\author{
Hua-An Lu*, Shu-Ling Chen**, and Peter Lai***
}

Key words: slot exchange, slot purchase, short sea service, slot allocation.

\begin{abstract}
In a slot exchange co-operation, participating carriers seek to benefit in which their surplus of controlled capacities can be shared to exchange slots belong to partners for their shortages. To each participant, whether the exchanged conditions can bring more benefits is based on its slot allocation planning. This paper introduces a practical slot exchange contract for multiple short sea loops between two co-operative carriers. Two integer programming models for maximizing the concerned profits are proposed to satisfy the expected demand level and shipping properties. One of the models merely considers slot exchange as the practical planning, and the other one includes slot purchase additionally. Decision results can assist the studied company to pursue an optimal allocation with consideration of exchanged slots for the involved lines. Moreover, sensitivity analyses including fixed exchanged condition, swap allowance influence, and purchase price assessment are carried out for measuring the impact of relevant variables to the profits.
\end{abstract}

\section{INTRODUCTION}

In contemporary liner shipping industry, alliance cooperation has been a popular approach adopted by carriers for extending service scopes and/or reducing investment risks. Concrete means of collaboration like joint fleet, slot charter, slot purchase, and slot exchange are normally employed in practice. This research focuses on a real-world case of slot exchange among short sea services. Slot exchange allows participating carriers to use the recognized capacities of the

Paper submitted 02/13/09; revised 07/09/09; accepted 09/28/09. Author for correspondence: Hua-An Lu (e-mail: halu@mail.ntou.edu.tw).

*Department of Shipping and Transportation Management, National Taiwan Ocean University, \#2, Pei-Ning Rd., Keelung 202, Taiwan, R.O.C.

**Department of Maritime and Logistics Management, Australian Maritime College Locked Bag 1397Launceston, Tasmania, 7250, Australia.

***Business Division-Asia Service Department, Yang Ming Marine Transport Corporation, \#271, Ming De $1^{\text {st }}$ Rd., Cidu, Keelung 206, Taiwan, R.O.C. involved lines not operated by own self, according to the contents of the agreement. In such co-operation, participating carriers expect to benefit in which their surplus of controlled slots can be shared to exchange capacities for their shortages. Accordingly, the exchanged condition must have a fair and reciprocal calculation among the involved lines between participants. If the number of exchanged slots cannot satisfy a carrier's estimated demand, extra available slots could be purchased from its partner as long as the deal is accepted by all of them. For fulfilling the benefit from the alliance contract as expectation, the carrier has to make an ideal slot allocation plan to understand the proposal of exchanged conditions. This research explores how to construct a beneficial proposal for the participating carrier.

The co-operative structures among liner companies began from conferences and consortia to the recent strategic alliances. Several studies have been devoted on the strategic alliances from different perspectives such as the exploration of cooperative purpose [7], motivations and successful reasons [14], and the main driving factors to yield the high degree of instabilities in the beginning of strategic alliances [12]. It was found that the obvious changes in the operations of liner shipping companies because of strategic alliances were the service networks and fleet composition and deployment $[13,16]$.

Slot allocation management is closely linked to container delivery that includes container movement control and empty container repositioning either sea services [2, 4, 8, 9, 15] or inland transports $[3,6,10]$. However, the availability of seaborne container movement depends on the planning of enough slot capacities. A few studies have treated the distribution of slot resources with the concept of revenue management or yield management for single port pair $[5,11]$, but this method fits for applying to the short-term planning before ship visiting during each voyage. Recently, Ang et al. [1] presented a yield maximization problem in considering cargos with various consigned periods from one port of origin to multiple ports of destinations. They formulated this problem as a multi-dimensional multiple knapsack model limited by the available empty containers, volume capacities and weight capacities. This research can only apply to the outbound slots distribution for a loading port.

To the best of our current knowledge, there is no description 
and formulation for practical slot exchange planning and alliance slot allocation. Ting and Tzeng [18] described the slot allocation problem of a liner service and proposed an integer programming model to obtain ideal allocated results for single directional traffic flows. This model can be only conducted on the case with the characteristics of the traffic pattern like an ocean-going service. Song and Panayides [17] suggested observing the operations of liner shipping strategic alliances from a co-operative game theory. They presented the simple examples for assessing the better coalition services in the cases of two players and more than two. Nevertheless, this conceptual introduction cannot provide the carrier a concrete planning procedure or structure applied to the practice yet.

In terms of the introduction of a practical case of slot exchange contract between two co-operative carriers, this study proposes two optimized allocation models stood at the viewpoint of one of participating carriers. The first model merely considers the slot exchange as the terms in the contract, while another one includes the allowance of slot purchase to satisfy the studied carrier's expectation. These two models can assess the level of concerned income under given part of information of its partners. The rest of this paper will introduce the treated problem in the next section, and then the contents and explanation of formulated models are followed. The assessment and parameter analysis of the considered case, which involves in total eight short sea services within Asia, will be reported from the viewpoint of the studied carrier. The final section concludes the findings and provides some suggestions for the future research.

\section{PROBLEM DESCRIPTION}

Slot exchange programs can be simple as conducting on a single loop of each carrier or complicated to involve multiple lines for each other. A simple case may just exchange slots one by one, but a complicated one may contain many routes with different service conditions. Ocean-going services are arranged for delivering transoceanic consignment. The service conditions on the market, like container transit time between port to port, deployed vessel types and main visiting ports, are normally similar among shipping lines. The slot exchange conditions may be simple to merely swap fixed number of slots for each other. On the other hand, short sea services seem more flexible in round trip voyage, cycle time, deployed vessel types and port rotation because their service scopes tend to cover more countries than transoceanic routes. These differences lead slot exchange conditions among short sea services more complicated than the ocean-going services. In any case, the most important thing for participants is to assess whether slot allocation of vessels can satisfy the expected carrying quantities within the scope of involved lines.

The studied company has been operating global container liner services for many years. This company sustained cooperative relationships with its strategic alliance partners through joint fleet and slot exchange. In order to intensify
Table 1. Service scopes and conditions for involved routes in the contract.

\begin{tabular}{llc}
\hline Line & \multicolumn{1}{c}{ Route and port rotation } & $\begin{array}{c}\text { Cycle time } \\
\text { (days) }\end{array}$ \\
\hline A1 & $\begin{array}{l}\text { Japan/Taiwan/Hong Kong/Thailand: } \\
\text { JPTYO } \rightarrow \text { JPYOK } \rightarrow \text { JPNGO } \rightarrow \text { JPOSA } \rightarrow \text { JPUKB } \rightarrow\end{array}$ & 28 \\
& JPOIT $\rightarrow$ TWKEL $\rightarrow$ TWKHH $\rightarrow$ HKHKG $\rightarrow$ THLCB $\rightarrow$ \\
& THBKK $\rightarrow \rightarrow$ HKHKG $\rightarrow$ TWKHH $\rightarrow$ TWTXG $\rightarrow$ \\
& TWKEL $\rightarrow$ JPTYO
\end{tabular}

A2 Japan/South Korea/Taiwan/Hong Kong/Singapore/ Indonesia: $\mathrm{JPMOJ} \rightarrow \mathrm{JPHKT} \rightarrow \mathrm{KRPUS} \rightarrow \mathrm{KRKWY} \rightarrow \mathrm{TWKEL} \rightarrow$ TWTXG $\rightarrow$ TWKHH $\rightarrow$ HKHKG $\rightarrow$ SGSIN $\rightarrow$ IDJKT $\rightarrow$ IDSUB $\rightarrow$ HKHKG $\rightarrow$ TWKHH $\rightarrow$ TWTXG $\rightarrow$ JPMOJ

A3 Taiwan/Philippines: TWKHH $\rightarrow$ TWKEL $\rightarrow$ PHMNS $\rightarrow$ PHMNN $\rightarrow$ TWKHH

B4 Japan/Taiwan/Hong Kong/Thailand: $\mathrm{JPTYO} \rightarrow \mathrm{JPYOK} \rightarrow \mathrm{JPNGO} \rightarrow$ JPOSA $\rightarrow$ JPUKB $\rightarrow$ TWKEL $\rightarrow$ TWTXG $\rightarrow$ TWKHH $\rightarrow$ HKHKG $\rightarrow$ $\mathrm{THLCB} \rightarrow \mathrm{THBKK} \rightarrow \mathrm{THLCB} \rightarrow \mathrm{HKHKG} \rightarrow$ TWKHH $\rightarrow$ TWKEL $\rightarrow$ JPTYO

B5 China/Hong Kong/Philippines/Indonesia: $\mathrm{CNTAO} \rightarrow$ CHSHA $\rightarrow$ HKHKG $\rightarrow$ PHMNN $\rightarrow$ PHMNS $\rightarrow$ IDJKT $\rightarrow$ IDSUB $\rightarrow$ CNTAO

B6 Japan/South Korea/Taiwan/Hong Kong: JPOSA $\rightarrow$ JPUKB $\rightarrow$ JPTYO $\rightarrow$ JPMOJ $\rightarrow$ KRPUS $\rightarrow$ KRKWY $\rightarrow$ TWKEL $\rightarrow$ TWKHH $\rightarrow$ HKHKG $\rightarrow$ JPOSA

B7 China/Hong Kong/Philippines/Thailand: $\mathrm{CNNGB} \rightarrow \mathrm{CNSHA} \rightarrow \mathrm{HKHKG} \rightarrow \mathrm{PHMNS} \rightarrow$ THLCB $\rightarrow$ THBKK $\rightarrow$ CNNGB

B8 Japan/Taiwan/Hong Kong/Vietnam: $\mathrm{JPNGO} \rightarrow \mathrm{JPTYO} \rightarrow \mathrm{JPYOK} \rightarrow \mathrm{TWKEL} \rightarrow \mathrm{TWKHH} \rightarrow$ $\mathrm{HKHKG} \rightarrow \mathrm{VNSGN} \rightarrow \mathrm{VNIHV} \rightarrow \mathrm{HKHKG} \rightarrow$ JPNGO

Source: the studied company

intra Asia services, the studied company also had some other co-operation with regional liner companies. This study focuses on a slot exchange contract between the studied company and one of its long-term partners, a local carrier providing some liner services within Asia. Their contract maintained a term of six months period. The exchanged conditions were reassessed for renewal before expiration. The data in this contract is collected for this research.

The contract between the studied company, denoted as Company A, and its partner, denoted as Company B, includes eight weekly service loops. Company A operates three of them and Company B operates the rest. These routes cover 24 ports in nine main countries within Asia (shown in Table 1). Although parts of the involved routes have same port rotation, A1 and B4, two companies enforced their service frequency in the indicated service scope through their alliance contract. Without considering the transhipment of containers, this study focuses on direct trade markets (or port pairs) in each loop. 
Table 2. Deployed ships and shared slots of involved routes in the contract.

\begin{tabular}{|c|c|c|c|c|c|c|c|}
\hline \multirow[b]{2}{*}{$\begin{array}{c}\text { Main } \\
\text { operator }\end{array}$} & \multirow[b]{2}{*}{ Line } & \multirow{2}{*}{$\begin{array}{c}\text { Number } \\
\text { of } \\
\text { deployed } \\
\text { ships }\end{array}$} & \multirow{2}{*}{$\begin{array}{c}\text { Contract } \\
\text { slots of a } \\
\text { ship } \\
\text { (TEUs) }\end{array}$} & \multicolumn{2}{|c|}{ Contributed ships } & \multicolumn{2}{|c|}{ Shared slots (TEUs) } \\
\hline & & & & $\begin{array}{c}\text { Company } \\
\text { A }\end{array}$ & $\begin{array}{c}\text { Company } \\
\text { B }\end{array}$ & $\begin{array}{c}\text { Company } \\
\text { A }\end{array}$ & $\begin{array}{c}\text { Company } \\
\text { B }\end{array}$ \\
\hline \multirow{3}{*}{$\begin{array}{c}\text { Company } \\
\text { A }\end{array}$} & $\mathrm{A} 1$ & 4 & 1100 & 4 & 0 & 1100 & 0 \\
\hline & $\mathrm{A} 2$ & 4 & 1100 & 4 & 0 & 1100 & 0 \\
\hline & A3 & 1 & 1100 & 1 & 0 & 1100 & 0 \\
\hline \multirow{5}{*}{$\begin{array}{c}\text { Company } \\
\text { B }\end{array}$} & B4 & 4 & 1100 & 1 & 3 & 275 & 825 \\
\hline & B5 & 4 & 1100 & 1 & 3 & 275 & 825 \\
\hline & B6 & 2 & 1100 & 0 & 2 & 0 & 1100 \\
\hline & B7 & 3 & 850 & 0 & 3 & 0 & 850 \\
\hline & B8 & 3 & 750 & 2 & 1 & 500 & 250 \\
\hline
\end{tabular}

Source: the studied company

There are 208 direct trades in total carried by Company A. These direct trade markets excludes consignments between domestic ports in some countries due to a cabotage limitation for foreign carriers to ship domestic cargoes.

According to the cycle time of each line, various numbers of ships are deployed on these lines for fulfilling their operational requirement of fixed weekly calls. It is noted that both companies have adopted joint fleet mode on three lines of Company B already, under another contract. As shown in Table 2, the slot share of each company corresponding to each line is calculated by multiplying contract slots of a ship by the ratio of respective number of contributed ships to total number of deployed ships. Both companies can use controllable capacities as a counter in the planning of slot exchanges.

All of involved routes have a variety of service contents with cycle times, scopes, and ship types and quantities. These dissimilarities imply that deploying capital and operating costs of each line could be different. Hence, it could hardly show the exact worth of slots on each line if the total number of exchanged slots was employed in the contract as an exchanged term. For this concern, both companies agreed to exploit a particular unit, namely TEU-day (TEU is twenty-foot equivalent unit of a standard container size), as the exchanged conditions, rather than using the total number of exchanged slots directly. The exchanged TEU-days for an alliance route are calculated by the product of the number of slots exchanged to partner and the cycle time in days of this service route. It is noted that the sum of exchanged TEU-days for all involved lines should be, therefore, equal for each company. Although the cycle time of a route cannot sufficiently represent the whole value of input resources, it is a simple way and also one of the important factors affecting the deploying costs of a service route.

According to the term of current slot exchange contract, both companies exchanged 19,250 TEU-days each other. In total, Company A swapped slots of 755 TEUs from its operating three lines for 875 TEUs of Company B's five operating lines. The total number of TEU-days is even for both companies as
Table 3. Slot exchanges in the current contract.

\begin{tabular}{|c|c|c|c|c|c|c|}
\hline \multirow{2}{*}{$\begin{array}{l}\text { Main } \\
\text { operator }\end{array}$} & \multirow{2}{*}{ Line } & \multirow{2}{*}{$\begin{array}{l}\text { Cycle time } \\
\text { (Days) }\end{array}$} & \multirow{2}{*}{$\begin{array}{l}\text { Slots exchanged } \\
\text { to partner } \\
\text { (TEUs) }\end{array}$} & \multirow{2}{*}{ TEU-days } & \multicolumn{2}{|c|}{$\begin{array}{c}\text { Current controlled } \\
\text { slot (TEUs) }\end{array}$} \\
\hline & & & & & $\begin{array}{c}\text { Company } \\
\text { A }\end{array}$ & $\begin{array}{c}\text { Company } \\
\text { B }\end{array}$ \\
\hline \multirow{4}{*}{$\begin{array}{c}\text { Company } \\
\text { A }\end{array}$} & $\mathrm{A} 1$ & 28 & 425 & 11,900 & 675 & 425 \\
\hline & $\mathrm{A} 2$ & 28 & 240 & 6,720 & 860 & 240 \\
\hline & A3 & 7 & 90 & 630 & 1010 & 90 \\
\hline & \multicolumn{2}{|c|}{$\begin{array}{l}\text { Total TEUs \& } \\
\text { TEU-days }\end{array}$} & 755 & $\underline{19,250}$ & & \\
\hline \multirow{6}{*}{$\begin{array}{c}\text { Company } \\
\text { B }\end{array}$} & B4 & 28 & 275 & 7,700 & 550 & 450 \\
\hline & B5 & 28 & 125 & 3,500 & 400 & 700 \\
\hline & B6 & 14 & 275 & 3,850 & 275 & 825 \\
\hline & B7 & 21 & 100 & 2,100 & 100 & 750 \\
\hline & B8 & 21 & 100 & 2,100 & 600 & 150 \\
\hline & \multicolumn{2}{|c|}{$\begin{array}{l}\text { Total TEUs \& } \\
\text { TEU-days }\end{array}$} & 875 & $\underline{19,250}$ & & \\
\hline
\end{tabular}

Source: the studied company

shown in Table 3. The final two columns in this Table present controlled slots of both companies after exchange. Besides the original shared capacities from the join fleet contract, Company A obtained more slots to be used on routes B4, B5 and B8 by the exchange contract.

\section{MODEL FORMULATION}

A proper slot exchange plan for a carrier aims to meet estimated demand levels and liner operational properties through effective slot allocation. From an individual company's standpoint, this paper proposes models for slot exchange planning and combining it with slot purchase. Without considering transhipment, this study focuses on direct trade markets (i.e. port pairs that can be finished seaborne carriage on a service route) in each loop as the concerns of the studied carrier. It is assumed that the range of demand quantities in each direct trade market is known and represented by lower and upper bounds. Moreover, we assume that the upper bounds of partner's available exchanges and possible shortages on each route are known in modelling. These parameters can be further explored their influences against the optimal decision with sensitivity analysis. Before introducing the formulated models, the first subsection describes a vital concept relative to the representation of the relationships between direct trade markets and sailing legs of each route.

\section{Route-Market-Leg Relationships}

At the planning period, the carrier is hardly to estimate the cargo mix for their consignment. To simplify cargo types by containers sizes, like 20 -foot and 40 -foot boxes, and/or special kinds of containers, such as reefer and out-of-gauge ones, becomes a popular way to estimate relative parameters. This alternative means each size of containers on the same market has homogeneous volume, weight and price in a long-term 


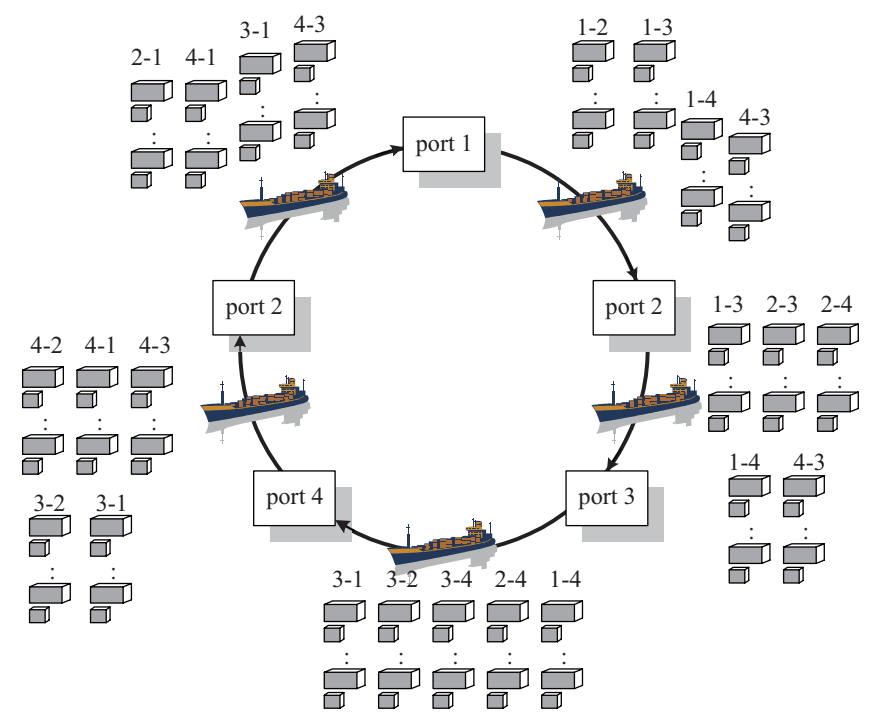

Fig. 1. Containers shipped on board for the illustrated example.

planning level. A liner can carry containers for all of trade markets among calling ports in a service route. However, its port rotation is unlikely able to provide non-stop deliveries for all port pair trades. Containers should be kept on board when the ship calls at other non-destination ports. This practice implies that some slots of the vessel may have been occupied by those transit freights loaded at previous port calls. Ideally, the vessel should be fully loaded at every sailing leg to achieve maximal utilization of slot capacities, but shipping company is unlikely to control shipments to meet such expectation in practice. According to the port rotation of a loop, the carried passages of consignments for every direct trade market can be acquired a priori from the load planning. These paths are normally arranged as the shortest one with minimal transit time due to market competition.

At the case with only one route, a market-leg relation parameter, $\alpha_{m s}$, with value of 1 or 0 defined as whether the delivery passage of consignments of direct trade market $m$ passing the sailing leg $s$ or not, 1 stands for yes and 0 otherwise. A round trip voyage with a port rotation 1-2-3-4-2-1 is illustrated here to depict the slot occupied relationships between trade markets and sailing legs as shown in Fig. 1. This example has 5 sailing legs for 5 calls and serves 12 port pairs because of visiting 4 different ports. It is clear that the carried containers of trade from port 2 to port 4 , for example, have to occupy the slots of legs 2-3 and 3-4. The value of corresponding market-leg relation parameters, $\alpha_{(2,4),(2,3)}$ and $\alpha_{(2,4),(3,4)}$, will be 1 , and others are 0 . The relationships for other markets and legs can be easily found.

Extending market-leg relationships to multiple routes, the route-market-leg relation parameter could be redefined as $\alpha_{m s}^{r}$ by adding an index of route $r$. It represents whether the consignments of direct trade market $m$ can be shipped by route $r$ and pass leg $s$ or not, 1 for yes and 0 otherwise. Besides the first route, another loop with rotation 1-2-4-2-1 is appended to
Table 4. Route-market-leg relation matrix $\left(\alpha_{m s}^{r}\right)$ for the illustrated example.

\begin{tabular}{cccccc|cccc}
\hline \multirow{2}{*}{$\begin{array}{c}\text { Trade } \\
\text { markets }\end{array}$} & \multicolumn{4}{c|}{$\begin{array}{c}\text { Route 1 }(r=1) \\
\text { Sailing legs }(s)\end{array}$} & \multicolumn{4}{c}{$\begin{array}{c}\text { Route } 2(r=2) \\
\text { Sailing legs }(s)\end{array}$} \\
\cline { 2 - 10 }$(m)$ & $1-2$ & $2-3$ & $3-4$ & $4-2$ & $2-1$ & $1-2$ & $2-4$ & $4-2$ & $2-1$ \\
\hline$(1,2)$ & 1 & 0 & 0 & 0 & 0 & 1 & 0 & 0 & 0 \\
$(1,3)$ & 1 & 1 & 0 & 0 & 0 & 0 & 0 & 0 & 0 \\
$(1,4)$ & 1 & 1 & 1 & 0 & 0 & 1 & 1 & 0 & 0 \\
$(2,1)$ & 0 & 0 & 0 & 0 & 1 & 0 & 0 & 0 & 1 \\
$(2,3)$ & 0 & 1 & 0 & 0 & 0 & 0 & 0 & 0 & 0 \\
$(2,4)$ & 0 & 1 & 1 & 0 & 0 & 0 & 1 & 0 & 0 \\
$(3,1)$ & 0 & 0 & 1 & 1 & 1 & 0 & 0 & 0 & 0 \\
$(3,2)$ & 0 & 0 & 1 & 1 & 0 & 0 & 0 & 0 & 0 \\
$(3,4)$ & 0 & 0 & 1 & 0 & 0 & 0 & 0 & 0 & 0 \\
$(4,1)$ & 0 & 0 & 0 & 1 & 1 & 0 & 0 & 1 & 1 \\
$(4,2)$ & 0 & 0 & 0 & 1 & 0 & 0 & 0 & 1 & 0 \\
$(4,3)$ & 1 & 1 & 0 & 1 & 1 & 0 & 0 & 0 & 0 \\
\hline
\end{tabular}

consider. The value of all parameters relative to the port 3 in the second route will be 0 because it is not visited in this loop. The market of port 2 to port 4 is a non-stop delivery, so the value of corresponding parameter, $\alpha_{(2,4),(2,4)}^{2}$, is 1 and 0 for others. The whole route-market-leg relationships for the example can be found in Table 4.

\section{Slot Exchange Model}

As noted, the carrier of using models is designated as Company A, while its partner is Company B. For ease of description, the following explanation will employ their roles. Besides, container types are categorized as container sizes and the number of types can follow the classification of Company A. The unit of slots is counted in terms of TEU in the models. Other symbols for variables and parameters used in the formulated models are introduced and interpreted as follows.

\section{Variables:}

$x_{m}^{r k}=$ number of distributing slots in TEUs for type $k$ container in market $m$ required on route $r$.

$q^{r} \quad=$ slots in TEUs to be exchanged to Company $\mathrm{B}$ on route $r$.

$n^{r} \quad=$ slots in TEUs to be exchanged from Company $\mathrm{B}$ on route $r$.

$\pi^{r}=$ a switch variable to represent exchanged slots from or to Company $\mathrm{B}$ on route $r, 1$ denotes from the partner and 0 otherwise.

$Q \quad=$ expected TEU-days to be exchanged in the contract.

$y^{r}=$ purchased slots in TEUs for the whole voyage on route $r$.

\section{Parameters:}

$S_{r} \quad=$ the set of sailing legs for route $r$.

$\alpha_{m s}^{r}=$ the route-market-leg relation parameter to represent whether the consignments of direct trade market $m$ 
can be shipped by route $r$ and pass leg $s$ or not, 1 for yes and 0 otherwise.

$p_{m}^{k} \quad=$ possible revenue received per type $k$ container to be delivered in market $m$.

$c_{m}^{k} \quad=$ required costs per type $k$ container to be delivered in market $m$.

$w^{k}=$ required slots in TEUs for loading type $k$ container, such as a 20 feet container occupies 1 TEU and a 40 feet container occupies 2 TEUs etc.

$U^{r} \quad=$ slots controlled by Company A on route $r$ in TEUs.

$b^{r} \quad=$ maximal slots that Company $\mathrm{B}$ can be released on route $r$ in TEUs.

$z^{r} \quad=$ Company B's possibly maximal shortage of slots on route $r$ in TEUs.

$t^{r} \quad=$ the cycle time of route $r$ in days.

$u_{m}^{k} \quad=$ estimated upper bound of carrying quantities for type $k$ container in market $m$.

$l_{m}^{k} \quad=$ estimated lower bound of carrying quantities for type $k$ container in market $m$.

$e^{r} \quad=$ purchased price per TEU for whole voyage on route $r$.

As the discussion above for slot distribution, it is noted that the carrier has to allocate suitable slots to various types of containers for each trade market along with possibly carried paths. Intuitively the capacities of a ship should be reserved with higher priorities for those containers with higher contributions to profit generation. However, too many overlaps of the carried paths within various markets increase the complexity of optimal allocation of slots, especially to take the slot exchange plan of multiple lines into account.

In this section, a mathematical model is constructed to decide the optimal amount of slot exchange with Company B to maximize Company A's profits. The formulated model [M1] is presented as follows.

[M1]

$$
\operatorname{Max} . \quad \sum_{r} \sum_{k} \sum_{m}\left(p_{m}^{k}-c_{m}^{k}\right) x_{m}^{r k}
$$

s.t.

$$
\begin{gathered}
\sum_{k} \sum_{m} \alpha_{m s}^{r} w^{k} x_{m}^{r k} \leq U^{r}-q^{r}+n^{r} \quad \forall r, s=1, \ldots,\left|S_{r}\right| \\
n^{r} \leq b^{r} \pi^{r} \quad \forall r \\
q^{r} \leq z^{r}\left(1-\pi^{r}\right) \quad \forall r \\
\sum_{r} t^{r} n^{r}=Q \\
\sum_{r} t^{r} q^{r}=Q \\
x_{m}^{r k} \leq U^{r} \sum_{s=1}^{\left|S_{r}\right|} \alpha_{s m}^{r} \quad \forall r, m, k
\end{gathered}
$$

$$
\begin{gathered}
\sum_{r} x_{m}^{r k} \leq u_{m}^{k} \quad \forall m, k \\
\sum_{r} x_{m}^{r k} \geq l_{m}^{k} \quad \forall m, k \\
\pi^{r} \in\{0,1\} ; x_{m}^{r k}, q^{r}, n^{r}, Q \geq 0 \text { and interger }
\end{gathered}
$$

The objective function in (1) maximizes the sum of estimated possible profits of Company A from shipping various types of containers among various trade markets. Since the contract of slot exchange or slot purchase is always discussed after route planning or service launch, the operational costs relative to ship sailing has to be absorbed by the carrier as the deployed vessels type no matter the result of cooperation. Slot allocation in considering slot exchange and slot purchase only concerns consignment revenues and container handling costs. Therefore, this paper takes into account the revenues that include average freight and any income from shippers and the costs that mainly contain all container handling charges occurring on loading and discharging ports. Port index for handling costs occurring is same as indexing by market. Equation (2) enforces that the sum of distributed slots on each sailing leg cannot exceed the available capacities, including the originally controllable slots plus the exchanged results. Equations (3) and (4) restrict each loop on exchanged slots either from or to Company B, and exchanged slots cannot exceed the maximal numbers that Company B could release or its possible shortage on each route. Equations (5) and (6) limit the numbers of exchanged TEU-days for both sides are consistent. The function of (7) is to ensure that the trade markets without on a specific route should not be allocated any slots on this service. Equations (8) and (9) constrain the allocated slots for a specific category and trade market falling into the range between its lower and upper bounds. If the planner can ensure a precisely number for the demand of a trade market, he/she can set the same value for its upper bound and lower bound. Equation (10) represents nonnegative and integral constraint of variables.

This model is an integer programming (IP) problem with several distributed variables concerned with the types of containers, involved routes and trade markets. As only direct trade markets on each line are considered, Eq. (7) will enforce many distributed variables to be 0 directly if involved lines do not appear too many duplicated trade markets. The number of other integer variables is only around three times of that of involved routes.

\section{Model Allowed Slot Purchase}

Slot purchase is another alternative adopted in an alliance agreement, particularly in the situation where Company B has had excess supply of capacities while the Company A is facing excess demand. In practice, the decision of slot purchase normally follows the result of slot exchange contract. However, the carrier can plan it simultaneously with the assessment 
of slot exchange when it holds enough information from the partner. The requirement for slot capacities is driven by the demand quantities. The carrier can adopt the slot allocation with higher profits in consideration both methods if partner's situation is available. Model [M2] aims to provide the optimal solution when partner's conditions and slot purchase price are given. Furthermore, slot purchase price is just able to represent the slot value in the whole context of the exchanged contract under the current demand levels for the company. In this section, the possibility of slot purchase is considered and another model [M2] is constructed as follows.

[M2]

$$
\operatorname{Max} . \quad \sum_{r} \sum_{k} \sum_{m}\left(p_{m}^{k}-c_{m}^{k}\right) x_{m}^{r k}-\sum_{r} e^{r} y^{r}
$$

$$
\begin{gathered}
\sum_{k}^{\text {s.t. }} \sum_{m} \alpha_{s m}^{r} w^{k} x_{m}^{r k} \leq U^{r}-q^{r}+n^{r}+y^{r} \quad \forall r, s=1, \ldots,\left|S_{r}\right| \\
y^{r}+n^{r} \leq b^{r} \quad \forall r
\end{gathered}
$$

(3) (10)

$$
y^{r} \geq 0 \text { and integer }
$$

The objective function of (11) maximizes the sum of profits from the possible carried containers after deducting the costs of slot purchase. Equation (12) replaces (2) to append the available slots from purchases. To the partner the available sold slots must be the left ones from the exchange contract. Equation (13) make the sum of partner's exchanged and sold slots on each line less than or equal to the maximal that it can release. Equation (14) is nonnegative and integral constraint for slot purchase variables. The structure of [M2] is similar as [M1] but increases the number of involved lines of variables and constraints. These two models can be solved by employing many commercial software packages for mathematical programming available today.

\section{COMPUTATIONAL RESULTS AND ANALYSIS}

This study used the commercial package of modelling language for mathematical programming, ILOG OPL Studio 3.5, to generate above formulations and to solve all instances by its embedded branch-and-bound algorithm. The relative data of this alliance were prepared for implementing solution on the personnel computer with the CPU of Intel Pentium 4, 2.4 GHz, and operation system of Microsoft Windows XP.

\section{Solving Results}

Because Company A only took into account 20-foot and 40-foot laden containers in slot planning, this study excluded empty and special kinds of containers. Both upper bounds of
Table 5. Comparisons of solving results between two models.

\begin{tabular}{lccc}
\hline Comparison items & $\begin{array}{c}\text { Slot exchange } \\
\text { only } \\
\text { (Model [M1]) }\end{array}$ & $\begin{array}{c}\text { Slot exchange with } \\
\text { 19,250 TEU-days } \\
\text { (Model [M1]) }\end{array}$ & $\begin{array}{c}\text { Slot exchange and } \\
\text { slot purchase } \\
\text { (Model [M2]) }\end{array}$ \\
\hline Number of variables & 3,353 & 3,352 & 3,361 \\
Number of constraints & 4,858 & 4,858 & 4,866 \\
Objectives (\$) & $4,079,670$ & $4,066,760$ & $4,234,460$ \\
Solving time (Sec.) & 2.55 & 4.64 & 1.60 \\
Slot exchanged (TEU-day) & 18,641 & 19,250 & 5,761 \\
Slots purchased (TEU) & 0 & 0 & 919 \\
\hline
\end{tabular}

available released slots from Company B $\left(b^{r}\right)$ and its possibly maximal shortage of slots $\left(z^{r}\right)$ are set as the current exchanged slots plus $10 \%$ more on each involved line. This condition, hereafter, is called the default swap allowance for distinguishing from the term of the current exchanged slots. This treatment could keep the original pattern in the contract and give more market flexibilities for obtaining possible optimal decision. Moreover, the most and least consigned numbers of containers of the studied company for every trade market are collected to be the upper and lower bounds of carrying quantities $\left(u_{m}^{k}\right.$ and $\left.l_{m}^{k}\right)$. The concerned costs of each container on each trade market include handling charges at ports. The revenues include the freight and terminal handling charge (THC) collected from the shippers. The purchase price of a slot is set as USD 300 for all of the routes according to Company A's suggestion.

This instance was solved with model [M1] considering slot exchange and further tested the instance at fixed exchanged TEU-days as the contract, i.e. 19,250 TEU-days. Model [M2] was also exploited to solve this instance incorporating slot purchase. As shown in Table 5, these cases can be obtained their optimal solutions within 5 CPU seconds. Furthermore, the results reveal that the studied company may reach the highest profit when its partner is willing to sell out slots of 919 TEUs and to exchange 5,761 TEU-days. If Company B is reluctant to sell them, then reducing the exchanged condition to 18,641 TEU-days rather than 19,250 TEU-days will generate a better profit. These results imply the default slot purchase price of USD 300 is lower than the profit that a unit slot might earn. Accordingly, Company A can purchase slots from Company B as many as possible to obtain the maximal profit under the optimal decision. In addition, the current exchanged slots in the contract indeed could not generate the maximal profit for Company A because of releasing too many slots for exchange with Company B. Company A, in fact, has the potential to strive for more consignments as long as Company B is ready to release capacities as Company A's willingness.

From the exchanged status of each line shown in Table 6, in merely consideration of slot exchange, Company $\mathrm{A}$ is able to release a few more slots to its partner on lines A1 and A3 but to reserve more to be used for its own on line A2. Moreover, the company can seek more exchanges than the current contract 
Table 6. Comparisons of current slot control and results of model solution.

\begin{tabular}{|c|c|c|c|c|c|c|c|c|c|c|c|}
\hline \multirow{3}{*}{$\begin{array}{c}\text { Main } \\
\text { operator }\end{array}$} & \multirow{3}{*}{ Line } & \multirow{2}{*}{\multicolumn{2}{|c|}{ Original control }} & \multirow{2}{*}{\multicolumn{2}{|c|}{ Current contract }} & \multirow{2}{*}{\multicolumn{2}{|c|}{ Model [M1] }} & & & & Unit: TEU \\
\hline & & & & & & & & \multicolumn{2}{|c|}{$\begin{array}{l}\text { Model [M1] with } \\
\text { 19,250 TEU-days }\end{array}$} & \multicolumn{2}{|c|}{ Model [M2] } \\
\hline & & $\begin{array}{c}\text { Company } \\
\text { A }\end{array}$ & $\begin{array}{c}\text { Company } \\
\text { B }\end{array}$ & $\begin{array}{c}\text { B swap } \\
\text { to A }\end{array}$ & $\begin{array}{c}\text { A swap } \\
\text { to B }\end{array}$ & $\begin{array}{l}\text { B swap } \\
\text { to A }\end{array}$ & $\begin{array}{l}\text { A swap } \\
\text { to B }\end{array}$ & $\begin{array}{c}\text { B swap } \\
\text { to A }\end{array}$ & $\begin{array}{l}\text { A swap } \\
\text { to B }\end{array}$ & $\begin{array}{l}\text { B swap } \\
\text { to A }\end{array}$ & $\begin{array}{l}\text { A swap } \\
\text { to B }\end{array}$ \\
\hline \multirow{3}{*}{$\begin{array}{c}\text { Company } \\
\text { A }\end{array}$} & $\mathrm{A} 1$ & 1100 & 0 & & 425 & & 436 & & 467 & & 181 \\
\hline & $\mathrm{A} 2$ & 1100 & 0 & & 240 & & 130 & & 196 & & 0 \\
\hline & $\mathrm{A} 3$ & 1100 & 0 & & 90 & & 99 & & 98 & & 99 \\
\hline \multirow{5}{*}{$\begin{array}{c}\text { Company } \\
\text { B }\end{array}$} & B4 & 275 & 825 & 275 & 0 & 302 & 0 & 302 & 0 & 0 & 0 \\
\hline & B5 & 275 & 825 & 125 & 0 & 131 & 0 & 137 & 0 & 0 & 0 \\
\hline & B6 & 0 & 1100 & 275 & & 302 & & 302 & & 302 & \\
\hline & B7 & 0 & 850 & 100 & & 109 & & 110 & & 73 & \\
\hline & B8 & 500 & 250 & 100 & 0 & 0 & 100 & 20 & 0 & 0 & 0 \\
\hline
\end{tabular}

Table 7. Allocated ratios of slot allocation for satisfying carrying demands.

\begin{tabular}{c|l|c|c|c}
\hline $\begin{array}{c}\text { Container } \\
\text { size }\end{array}$ & $\begin{array}{c}\text { Number and ratio for } \\
\text { allocation }\end{array}$ & $\begin{array}{c}\text { Model } \\
{[\mathrm{M} 1]}\end{array}$ & $\begin{array}{c}\text { Model [M1] } \\
\text { with 19,250 } \\
\text { TEU-days }\end{array}$ & $\begin{array}{c}\text { Model } \\
{[\mathrm{M} 2]}\end{array}$ \\
\hline \multirow{5}{*}{ 20-foot } & $\begin{array}{l}\text { Meet with the lower } \\
\text { bound }\end{array}$ & $\begin{array}{c}33 \\
(15.8 \%)\end{array}$ & $\begin{array}{c}51 \\
(24.5 \%)\end{array}$ & $\begin{array}{c}28 \\
(13.4 \%)\end{array}$ \\
\cline { 2 - 5 } & $\begin{array}{l}\text { Meet with the upper } \\
\text { bound }\end{array}$ & $\begin{array}{c}171 \\
(82.2 \%)\end{array}$ & $\begin{array}{c}154 \\
(74.1 \%)\end{array}$ & $\begin{array}{c}176 \\
(84.6 \%)\end{array}$ \\
\cline { 2 - 5 } & $\begin{array}{l}\text { Fall between lower } \\
\text { and upper bounds }\end{array}$ & $\begin{array}{c}4 \\
(2.0 \%)\end{array}$ & $\begin{array}{c}3 \\
(1.4 \%)\end{array}$ & $\begin{array}{c}4 \\
(2.0 \%)\end{array}$ \\
\hline \multirow{5}{*}{$40-$ foot } & $\begin{array}{l}\text { Meet with the lower } \\
\text { bound }\end{array}$ & $\begin{array}{c}35 \\
(16.8 \%)\end{array}$ & $\begin{array}{c}80 \\
(38.4 \%)\end{array}$ & $\begin{array}{c}25 \\
(12.0 \%)\end{array}$ \\
\cline { 2 - 5 } & $\begin{array}{l}\text { Meet with the upper } \\
\text { bound }\end{array}$ & $\begin{array}{c}169 \\
(81.2 \%)\end{array}$ & $\begin{array}{c}115 \\
(55.4 \%)\end{array}$ & $\begin{array}{c}177 \\
(85.1 \%)\end{array}$ \\
\cline { 2 - 5 } & $\begin{array}{l}\text { Fall between lower } \\
\text { and upper bounds }\end{array}$ & $\begin{array}{c}4 \\
(2.0 \%)\end{array}$ & $\begin{array}{c}13 \\
(6.2 \%)\end{array}$ & $\begin{array}{c}6 \\
(2.9 \%)\end{array}$ \\
\hline
\end{tabular}

on lines B4, B5, B6 and B7 if possible. Obviously, Company A had less carrying requirement on line $\mathrm{B} 8$, and should release some controlled capacities rather than to acquire more. From this analysis, we conclude that lines $\mathrm{A} 2$ and B4 to B7 are of lacking slots but lines A1, A3 and B8 were of having extra ones to the studied company. Combining with the possibility of slot purchase, Company A can obtain slots as many as possible in terms of this way at the current price. Slot exchange can only take lines A1, A3, B6 and B7 into account.

Among the 208 O-D pairs, solving results show that Company A can provide almost port pairs the most slot ratios reaching their demand upper bounds for 20-foot and 40-foot containers. Using [M1] and [M2] models can exceed $80 \%$, but these ratios decrease to $74.1 \%$ and $55.4 \%$ respectively at fixing TUE-days with 19,250 for solving Model [M1]. Only less than $7.0 \%$ of port pair demands are satisfied falling between lower and upper bounds in all solving cases. Other parts are those which can satisfy the lower bounds at least. This analysis is displayed in Table 7. In the comparison of Tables 7 and 5,

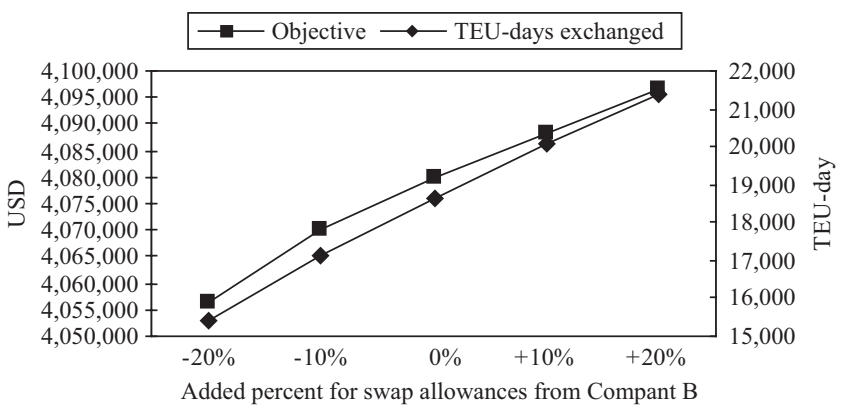

Fig. 2. Influences of swap allowances on objective and TEU-day.

the more the objective value, the higher the ratios of meeting with the upper bounds in slot allocation. It makes sense at the input-output verification for the validity of our proposed models.

\section{Analysis for Swap Allowance}

In this section we further examine the influences of the swap allowances from Company B (i.e. $b^{r}$ and $z^{r}$ ) to the objective and exchanged TEU-days. The extension range is from $20 \%$ downward to $20 \%$ upward of the default swap allowance. Solving with the model [M1], the maximal profit and the exchanged TEU-days are positively associated with adjustments of the swap allowances as shown in Fig. 2. When the swap allowances increase, the maximal profit and the optimal exchanged TEU-days will increase as well. However, the increased margin is larger at the swap allowance is lower $10 \%$ than the default value, i.e. the current exchanged slots in the contract, and is smaller at exceeding it.

Note that it is infeasible when reducing the swap allowance to $30 \%$ less than the default value because the least slot demands on some trade markets of the company can not be satisfied at such low allowance level. Company A indeed needs slot exchanges to support its strong market demand for chasing more benefits by courtesy of more swap allowances from Company B. 


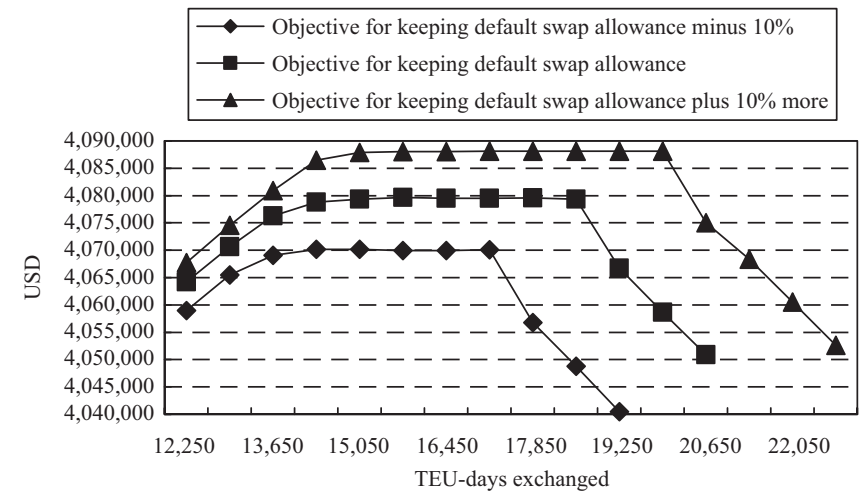

Fig. 3. Fixed exchanged TEU-days analysis for various swap allowances.

\section{Fixed TEU-Days Analysis}

In practice, the bargain results for slot exchange with the partner are normally different from the company's initial plan because the partner's intention could not be predicted precisely in advance. This section aims to explore the optimal profit levels for Company A with various fixed TEU-days. The number of exchanged TEU-days is upward and downward from 19,270 by a scale of 700 TEU-days at a time. It is noted that the number of TEU-days must be the multiples of 7 because of weekly service on each line. Three levels of swap allowance are considered, i.e. the default number and $10 \%$ less and $10 \%$ more of that.

At the case of default swap allowance, the results show that the profits in model [M1] are almost the same between 14,350 and 18,550 TEU-days (see Fig. 3). However, the profit generated by the current contracted exchanged TEU-days of 19,250 is lower than that. Other two cases show that the greater is the swap allowance the higher is the profit. In addition, the change pattern of profits with various TEU-days in these two cases is same as the first one. Obviously, the range of TEU-days with maximal profits becomes lager as the swap allowance increases. When TEU-days fall below this range, the profit will gradually increase as it increases. On the other side, the profits sharply decrease when TEU-days increase and no feasible solution exists at TEU-days larger than a certain number. The critical numbers in three cases are 19,250, 20,650 and 22,750 TEU-days, respectively.

The curves in Fig. 3 are of meaningfulness for the studied company because involved lines are all restricted within the short sea services in Asia. The differences of unit profits for the same category of laden containers in various trade markets are slight. This analysis suggests that Company A could easily adjust the slot allocation to obtain the better profits for a fixed number of exchanged TEU-days. Certainly, the incremental margin would be moderated when the enforced exchanged TEU-days are lower than the critical one. Contrarily, the profit will rapidly loose due to the slot resources are wasted to exchange with Company B rather than to load the boxes with actual incomes. If the wastes are spreading more, ship's slots cannot afford to satisfy the least carrying demand finally. This

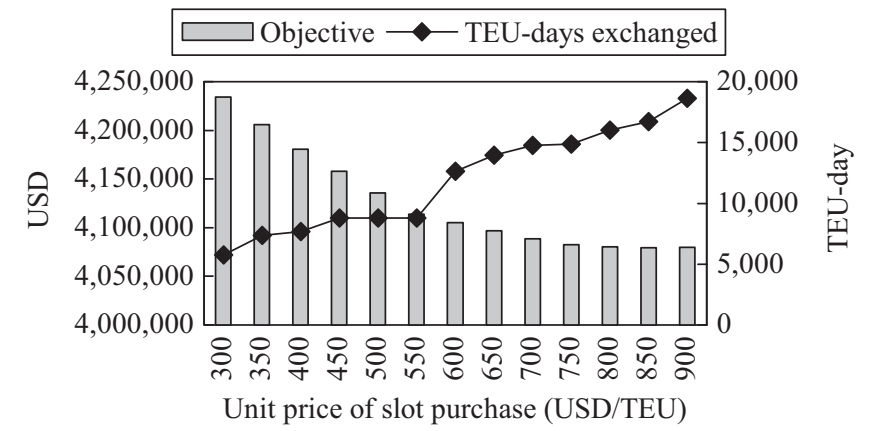

Fig. 4. Sensitivity analysis of slot purchase price.

analysis is valuable for the Company A to realize the suitable levels of exchanged TEU-days and critical edge of slot resources.

\section{Price Analysis for Slot Purchase}

Model [M2] considers slot purchase in the slot exchange agreement to reflect the value of unit slot resource for Company A. It shows, in section of solving results, that the suggested slot purchase price of USD 300 is lower than the operating value of Company A's own and can contribute to an increase in profit for it at a decrease in exchanged TEU-days. This result implies that the studied company should purchase slots as many as possible from Company B rather than executing slot exchange. Rationally, if Company B realized the market value of unit slot to Company A, it might not sell any slot at this price for the reason of competition unless this deal also benefits Company B.

Accordingly, we carried out a price sensitivity analysis to find out the acceptable level of slot purchase price for Company A. Additional USD 50 is added to the unit purchase price at a time for analysis. As shown in Fig. 4, the profits reduce as the unit price increases because of extra expenses of purchasing, and the decrement is diminishing. On the other hand, the number of exchanged TEU-days increases associated with an increase in unit purchase price, but there is an abrupt lift of exchanged TEU-days at the prices between USD 550 and 600 following a smooth change path. When the purchase price reaches USD 850, the solution does not appear any purchased slot. The critical price locates at USD 841 through further tests. It is found that Company A does not adopt slot purchase policy any more when the unit purchased price is over it. This price could be a reference in pricing slots sold to its partner or other carriers. If Company A could sell the slot with the price higher than this one, it rather did than operated by self. Note that the critical price of Company B is not the same as this price because its demands on these lines are different.

We further explored the critical purchase prices for Company A in terms of five swap allowances from Company B. As shown in Table 8, the critical purchase price rises as the swap allowance increased, but the range is nearly small at the allowance enlarged more than the default case. The profits 
Table 8. Critical purchase prices of the unit slot under various swap allowances.

\begin{tabular}{cccc}
\hline $\begin{array}{c}\text { Swap } \\
\text { allowance }\end{array}$ & $\begin{array}{c}\text { Critical purchase } \\
\text { price } \\
\text { (USD/TEU) }\end{array}$ & $\begin{array}{c}\text { Objective } \\
\text { (USD) }\end{array}$ & $\begin{array}{c}\text { TEU-days } \\
\text { exchanged } \\
\text { (TEU-day) }\end{array}$ \\
\hline$-20 \%$ & 781 & $4,056,080$ & 13,384 \\
$-10 \%$ & 800 & $4,069,910$ & 17,150 \\
Default & 841 & $4,079,670$ & 18,641 \\
$+10 \%$ & 845 & $4,088,380$ & 18,088 \\
$+20 \%$ & 846 & $4,096,610$ & 17,688 \\
\hline
\end{tabular}

increase but with a diminishing tendency. However, the exchanged TEU-days do not show an increasing path when the swap allowance is larger than the default case.

The critical purchase price would be regarded as the value of unit slot for the studied company only executing slot exchange. Optimal slot allocation tends to shift slot resources to the most usage for obtaining the maximal profit. Since the profits are growing as the flexibility of exchange increases, the slot value still grows. Exchanged TEU-days reflect the adjustments of slot allocation according to the slot availabilities of each line. When the swap allowance is enlarged to $10 \%$ more than the default case, slot allocation has more effective results so that the numbers of TEU-days exchanged can be reduced.

\section{CONCLUSIONS AND SUGGESTIONS}

Under alliance co-operation, carrier's decision-making in how to execute slot exchange with its partners is an important part of its slot allocation plan, which links to company's profitability. Based on an operating slot exchange contract between two carriers, this study has contributed two models aiming to assist carrier distributing slots in optimal slot exchange and with consideration of slot purchase for the involved lines. These models could also generate results revealing which lines should release capacities or swap slots according to the estimated demands of direct trade markets. Hence, they can be extendedly applied to a survey regarding which lines should be involved in the alliance contract.

Important findings of this study in respective of slot allocation in the slot exchange alliance are concluded as follows.

1. In the short sea services, the optimal profits from various slot exchanges appeared to be the same within a range of exchanged TEU-days. The increment margin of profits was moderated as exchanged TUE-days increases and less than the range. However, the profits rapidly decreased as the exchanged TEU-days went beyond the critical range until no way to satisfy the least carrying demand because of slot resources wasting on exchange conditions.

2. Swap allowance levels released from the partner dominated the context of slot exchange. Given a strong carrying de- mand, the profits and exchanged TEU-days positively associated with the change of swap allowances.

3. Given that slot purchase was allowed and when the purchase price was lower than the profit gained from slot exchange without purchase, the studied company would have a better profit by adopting a slot exchange and purchase strategy.

4. The critical slot purchase price reflected the maximal profit that the unit slot could be earned from the studied carrier's viewpoint. It could be a valuable reference given to the studied company when considering selling in slots to its partner or others.

This paper dealt with a practical case. The test cases only focused on the scale of the introduction in Section II. No matter the report in Table 5 or other cases in sensitivity analysis, the commercial optimization package could solve them in efficiency. In theory, future studies can consider developing effective algorithm that can handle the larger cases in rational time.

Slot allocation planning is a vital issue of slot management in liner's practical operations. It becomes more complicated especially after permeating alliance operations as the different characteristics of each kind. The slot exchange contract presented in this research is only a specific case between the studied carrier and its partner. Different alliance agreement and more involved parties will lead to more valuable study topics for researchers. Moreover, models presented in this research are based on the standpoint of one participant. Some data regarding the partner must be ready in hand. If liner carrier would apply to it, these parameters could be collected in the process of bargaining and modified gradually. In the future research, the win-win models can be developed on the basis of mutual agreement.

\section{ACKNOWLEDGMENTS}

This research was partially supported by a grant (NSC962416-H-019-008) from the National Science Council of Taiwan. We also thank Mr. Jackie Chen, manager of Yang Ming Marine Transport Corporation, for providing valuable knowledge and practical viewpoint regarding alliance co-operation.

\section{REFERENCES}

1. Ang, S. K., Cao, C., and Ye, H. Q., "Model and algorithms for multiperiod sea cargo mix problem," European Journal of Operational Research, Vol. 180, pp. 1381-1393 (2007).

2. Cheung, R. K. and Chen, C. Y., "A two-stage stochastic network model and solution methods for the dynamic empty container allocation problem," Transportation Science, Vol. 32, No. 2, pp. 142-162 (1998).

3. Crainic, T. G., Gendreau, M., and Dejax, P., "Dynamic and stochastic models for the allocation of empty containers," Operations Research, Vol. 41, pp. 102-126 (1993).

4. Gao, Q., "An operational approach for container control in liner shipping," Logistics and Transportation Review, Vol. 30, No. 3, pp. 267-282 (1994). 
5. Ha, D. W., Capacity Management in the Container Shipping Industry: The Application of Yield Management Techniques, Ph.D. Dissertation, Department of Marketing, Logistics and Transportation, University of Tennessee, Knoxville (1994).

6. Jula, H., Chassiakos, A., and Ioannou, P., "Port dynamic empty container reuse," Transportation Research Part E, Vol. 42, pp. 43-60 (2006).

7. Kadar, M., The Future of Global Strategic Alliances, Containerization International, Apr. pp. 81-85 (1996)

8. Lai, K. K., Lam, K., and Chan, W. K., "Shipping container logistics and allocation," The Journal of the Operational Research Society, Vol. 46, No. 6, pp. 687-697 (1995).

9. Li, J. A., Leung, C. H., Wu, Y., and Liu, K., "Allocation of empty containers between multi-ports," European Journal of Operational Research, Vol. 182, No. 1, pp. 400-412 (2007).

10. Lopez, E., "How do ocean carriers organize the empty containers reposition activity in the USA?" Maritime Policy and Management, Vol. 30, No. 4, pp. 339-355 (2003).

11. Maragos, S. A., Yield Management for the Maritime Industry (Shipping, Itineraries), Master Dissertation, Department of Ocean Engineering, Massachusetts Institute of Technology, Cambridge, MA (1994).
12. Midoro, R. and Pitto, A., "A critical evaluation of strategic alliances in liner shipping," Maritime Policy and Management, Vol. 27, No. 1, pp. 31-40 (2000).

13. Ryan, D'A. J., Strategic Alliances and Their Impacts on the Container Shipping Industry, Master Thesis, Department of Geography, Concordia University, Montreal, Quebec (2001).

14. Ryoo, D. K. and Thanopoulou, H. A., "Liner alliances in the globalization era: A strategic tool for Asian container carriers," Maritime Policy and Management, Vol. 26, No. 4, pp. 349-367 (1999).

15. Shen, W. S. and Khoong, C. M., "A DSS for empty container distribution planning," Decision Support Systems, Vol. 15, pp. 75-82 (1995).

16. Slack, B., Comtois, C., and McCalla, R., "Strategic alliances in the container shipping industry: A global perspective," Maritime Policy and Management, Vol. 29, No. 1, pp. 65-76 (2002).

17. Song, D. W. and Panayides, P. M., "A conceptual application of cooperative game theory to liner shipping strategic alliances," Maritime Policy and Management, Vol. 29, No. 3, pp. 285-301 (2002).

18. Ting, S. C. and Tzeng, G. H., "An optimal containership slot allocation for liner shipping revenue management," Maritime Policy and Management, Vol. 31, No. 3, pp. 199-211 (2004). 